\title{
MEMORY AND REFLECTION
}

\section{Chienkuo $M i^{1}$}

\begin{abstract}
I have argued that the Analects of Confucius presents us with a conception of reflection with two components, a retrospective component and a perspective component. The former component involves hindsight or careful examination of the past and as such draws on previous learning or memory and previously formed beliefs to avoid error. The latter component is foresight, or forward looking, and as such looks to existing beliefs and factors in order to achieve knowledge. In this paper, I raise the problem of forgetting and argue that most of contemporary theories of knowledge have to face the problem and deal with the challenge seriously. In order to solve the problem, I suggest a bi-level virtue epistemology which can provide us with the best outlook for the problem-solving. I will correlate two different cognitive capacities or processes of "memory" (and "forgetting") with the conception of reflection, and evaluate them under two different frameworks, a strict deontic framework (one that presupposes free and intentional determination) and a more loosely deontic framework (one that highlights functional and mechanical faculties). The purpose is to show that reflection as metacognition plays an important and active role and enjoys a better epistemic (normative) status in our human endeavors (cognitive or epistemic) than those of first-order (or animal) cognition, such as memory, can play.
\end{abstract}

Keywords: Memory. Virtue Epistemology. Reflection.

1. It is a common practice to view memory as a "store-house" of our past experiences and learned materials. However, it will lead naturally to the following questions and puzzles: where do we store (or retain) our memory? How do we maintain our memory? What does it mean to say that we remember something in the past? And how can we be sure that our memory is reliable, justifiable, or competent enough? Forgetting, by contrast, is usually regarded as the loss of memory or inability to recall past information. It appears to be the case that "memory" and "forgetting" are always opposite to each other,

${ }^{1}$ Distinguished Professor of Philosophy, Soochow University, Taipei City - Taiwan. (D) https://orcid. org/0000-0003-3461-3713 E-mail: cmi@scu.edu.tw

https://doi.org/10.1590/0101-3173.2021.v44dossier2.10.p151 
especially for the most of the western philosophers or epistemologists, and that "memory" plays a normal and vital role in general while "forgetting" a malfunctioning and unwanted one.

John Locke has characterized human's faculty of forming and functioning memory as a process of imprinting, storing (or furnishing), and retrieving (or reviving) various ideas. He described this so-called memory process as a way in which "(our) senses at first let in particular Ideas, and furnish the yet empty Cabinet: And the Mind by degrees growing familiar with some of them, they are lodged in the Memory, and Names got to them. . . . Memory is the power to revive again in our minds those ideas which after imprinting have disappeared, or have been laid aside out of sight." (An Essay Concerning Human Understanding: Chapter X) In contemporary psychology, this process is commonly understood as a three-stage process: memory encoding, memory storage, and memory retrieval (whatever the content of memory may be). To remain neutral to different standings and possible theories regarding the nature of memory, I prefer to treat the memory process as a 3-RE process: Receiving (RE-1), Retaining (RE-2), and Recalling (RE-3). It is important to acknowledge that if we view memory as a process (long term or short term), then forgetting can happen at any point of this memory process. Forgetting can occur at the RE- 1 when we fail to imprint or encode the inputting information properly. It can also occur at the RE-2 if the retained materials are erased accidentally or left aside carelessly. And it can occur at the RE-3 when we are not able to recall or retrieve the information we need, for whatever reasons.

Recent researches in psychology and philosophy (East and West) have shown or argued that forgetting is sometimes necessary for our psychological and cognitive wellness, and that forgetting can be virtuous as an ethical or epistemic factor. If it is true, then "forgetting" will post a threat and a challenge to the main theories in contemporary epistemology. I will argue, based on an improved version of Ernest Sosa's bi-level virtue epistemology, that in order to deal with the challenge and solve the problem (of forgetting), an intellectual (or moral) agent has to learn and develop a well-balanced competence (or character-trait) of "memory (encoding/retaining (or maintaining)/decoding)" and "forgetting (ignoring/recycling (or sedimenting)/abstracting)". 
2. So, what is the problem that forgetting might bring about for the theories of knowledge? We can explore the following reasonings and track the problem step by step.

a. The problem of forgetting for epistemic internalism

1. $S$ knows that $P$ if and only if S's true belief that $P$ is justified (plus any anti-luck condition which can avoid or overcome any Gettierstyle counter-example).

2. Memory is one of the important sources of justification or grounds for attaining our knowledge (or well-grounded justified true belief).

3. Forgetting is alway the opposite of memory, so forgetting itself cannot be a source of justification or ground for attaining our knowledge (Forgetting is a defeater of our awareness of the justification).

4. However, forgetting can also be a source of justification or ground for attaining our knowledge (cf. Madison's argument of forgetting as memory-seeming).

5. 3. and 4. are inconsistent.

6. Therefore, we have a problem (of forgetting) for epistemological internalism.

b. The problem of forgetting for epistemic externalism

1. S knows that $\mathrm{P}$ if and only if $\mathrm{S}$ 's true belief that $\mathrm{p}$ is formed through a reliable process.

2. Memory is one of the reliable processes through which we can form our true beliefs.

3. Forgetting is always the opposite of memory, so forgetting itself is not a reliable process of forming our true belief (Forgetting cannot contribute to the generation of a reliable process). 
4. However, forgetting can also be a reliable process of forming our true beliefs. (cf. Bernecker's argument of forgetting as generative process)

5. 3. and 4. are inconsistent.

6. Therefore, we have a problem (of forgetting) for epistemological externalism.

c. The problem of forgetting for virtue epistemology

1. S knows that $\mathrm{P}$ only if $\mathrm{S}$ 's forming true belief that $\mathrm{P}$ manifests his or her relevant intellectual virtues.

2. Memory is one of the intellectual virtues in virtue of which we can form our true beliefs. (Memory is a positive and active source of knowledge.)

3. Forgetting is the opposite of memory, so forgetting itself is not an intellectual virtue. (Forgetting is a cognitive vice)

4. However, forgetting has been proved (or at least can be proved) as one of the important moral or intellectual virtues. (cf. Michaelian or Zhuangzi's arguments)

5. 3. and 4. are inconsistent.

6. Therefore, we have a problem (of forgetting) for Virtue Epistemology.

The steps 3. in all three reasonings above are in correspondence to our common-sense of forgetting. By the common-sense of forgetting, it is understood as the opposite of memory or the negation of memory (memoryloss or memory-failure). In this way, forgetting is thus correlate to the three steps 3., namely, forgetting is a defeater of our awareness of justification; forgetting cannot contribute to the generation of a reliable process; and forgetting is a cognitive or epistemic vice. Nevertheless, several philosophers (East and West) have argued for the steps 4. that some patterns of forgetting have positive function, or at least some patterns of forgetting (in its active form) are unlike what the steps 3. have suggested. 
3. Why is virtue epistemology vulnerable to the challenge of the problem of forgetting? Among various intellectual virtues or epistemic virtues, whether they are character-based or competence-based virtues, memory is hardly noticed by virtue epistemologists, not to mention the idea of forgetting. Sosa's position, as usually described as a kind of competencebased virtue epistemology, will allow the idea of memory (a good and reliable one) as a first-order competent cognitive capacity or mechanism, and thus a kind of first-order epistemic virtue. However, he has never considered the idea of forgetting as any kind of virtue (and I am not sure if he will take it as some kind of epistemic vice). Others, while propose and praise many different character-based intellectual virtues like humility, open-mindedness, curiosity and so on, have never put memory in their list. I can also imagine that it will be outrageous for them to include forgetting as any kind of intellectual virtue. So, how should we convince them to seriously consider the problem of forgetting?

Let's introduce an example which I hope can attract at least some of virtue epistemologists (or even some philosophers in general), and can drive them to think about and to deal with the problem more seriously and carefully. The example I am going to use is called "The Password Case". Ernie receives a message from his bank in which a long series digit password, say, RSbh\#49835TG, is set and given to him for his e-banking account. Apart from this long series digit password for e-banking account, he has several other long series digit passwords for email accounts, journal author accounts and internet access accounts. It would be very difficult for him to remember all the different passwords. Instead of remembering the e-banking account password, Ernie decides to "forget it" and save the number on his secret pocket book (so he can reach it anytime when he needs it). Practically speaking, it seems to be a more reliable way for Ernie to forget the password rather than to memorise it. To forget the password, Ernie seems to gain prima facie justification for believing that e-banking account is RSbh\#49835TG which would be safely remained (in his pocket book). If this is correct, it would be an intellectual or epistemic virtue attributed to Ernie to forget but not to remember in this case. It seems plausible in turn that he might seem to know that his e-banking account password has been established as RSbh\#49835TG, even he has forgotten now what the password is and how, when and where he established the password, as well as any other passwords he might have had. The reason why Ernie still knows the password is because he can always show you the correct number (by showing the number in his pocket book) every time you 
ask for it. Therefore, Ernie knows his e-banking password, in this case, because he has the epistemic virtue of forgetting the password number.

How could we explain, in this password case, that forgetting can become an epistemic virtue against the common-sensical view that forgetting always plays a malfunctioning and unwanted role? In this case, forgetting here is still the opposite of memory. It is because Ernie realises that he cannot remember the long series digit password, he decides to forget it. Why does Ernie's decision make forgetting in this case virtuous? In what follows, I want to argue the agency behind the scene that pushes Ernie to forget the password does play a vital role and explains why forgetting can also become a virtue, intellectual or epistemic.

4. To deal with the issues raised above, I would like to bring in Ernest Sosa's framework of performance-based normativity first. "Performance" is a very broad or general concept which can cover all kinds of performance: art, sports, morality, cognition, philosophy, science, various professional performance, and even functional performance. There are three elements of a good performance according to Sosa: accuracy, adroitness, and aptness. An archer's shot, to repeat Sosa's famous example, would be accurate if it hits the target; it would be adroit if the archer shoots skilfully; and it would be apt if the accurate shot is because of (or manifests) the archer's adroit skill. This is called by Sosa the 3-A model of evaluating a performance. A good performance requires the presence of all three elements. Similarly, when it comes to a good piano performance, the performance should be accurate, there should be a correct rendition of the target piece, and the performance would be adroit in that the performer will be competent. That is not all, however. A good performance will be apt. What Sosa means by this is that the performance will be accurate because of adroitness.

In epistemology, belief-forming process (as a cognitive performance) follows the same structure (or the same model) above. A belief is accurate if and only if it is true. The formation of a belief may be adroit - the belief may be formed because of perception, memory, deduction, or other competent ways of forming beliefs. Crucially, a belief is apt if and only if the belief is accurate (that is, true) because of adroitness (showing performer's or believer's epistemic or intellectual virtues). As Sosa has also pointed out that Aristotle expresses the very same idea in his works as well: "It is possible to do 
something that is in accordance with the laws of grammar, either by chance or at the suggestion of another. A man will be a grammarian, then, only when he has both done something grammatical and done it grammatically; and this means doing it in accordance with the grammatical knowledge in himself" (Aristotle, NE II4, 1105a22-6). A man can do something grammatical (or some virtuous things), and therefore such doing is itself accurate. A man can also do something grammatically (or virtuously), and he therefore shows his competence or adroitness. But a man can be called a genuine grammarian (or a truly virtuous agent) only if he has done some grammatical things grammatically (or some virtuous things virtuously). The grammarian (or a virtuous agent) has therefore been performing aptly.

5. In addition to the performance-based normativity, it is also important to introduce the bi-level performance or bi-level virtue epistemology. Let's consider Diana's performance (again, using Sosa's own example): An archer simply fires his arrow and hits the target because of the first-order competence of the archer. Now a more skilled huntress may get the same result. She too may hit the target, and it may be said that she too hit the target because of ability, a good shot by an archer is a first-order apt performance. However, shot selections would be integral to the competence of Diana the huntress. The agent (Diana the huntress) must perform aptly (in order to perform full well or fully apt) not only in light of her higher-order apt belief that she would perform (first-order) aptly, but also guided by that higher-order belief. Diana thus needs the higher-order competence to assess her own first-order competence and its required conditions (such as her personal shape and the situational conditions) as well. She needs to make the risk assessment carefully before the shot is taken. Diana's shot would be apt if and only if its accuracy manifests Diana's adroitness. It would be reflectively competent (manifesting Diana's higher-order aptness) if and only if it corresponds to a competent higher-order awareness that her shot would be apt. Diana's greater skill may be manifest in her performance, and that at least some of this greater skill may be accounted for as second-order competence. While the more skilled huntress may fire her arrow in just the same way as the performance by the normal archer, the thought is that when manifesting greater skill she will be at least sensitive to matters such as whether the wind is likely to effect her shot, whether there are any unseen obstacles to a successful performance. 
Knowledge performance or belief-forming process (as a kind of cognitive performance) is a special case for this bi-level performance again. We might call the kind of epistemology involved here a kind of bi-level virtue epistemology. Performance with full aptness would normally require knowing that one would then perform aptly. This is the knowledge that must guide one's performance if it is to be fully apt. Epistemic agents do not just aim for correctness of affirmation. They also judge, aiming for aptness of affirmation. So, even a properly confident subject who affirms aptly might fail with his judgment. Because even while affirming aptly in the endeavour to affirm correctly, he might fail to judge aptly. In other words, the epistemic agent's alethic affirmation, aimed at truth, might be apt (at the first-order) without being fully apt, in which case his judgment would not be apt (at the higherorder). Judgment is affirmation in the endeavour to affirm aptly. In judgment one aims to alethically affirm aptly. Judgmental affirmation that p must hence manifest competence not only to get it right on the question whether $\mathrm{p}$, but also to do so aptly. In order for a judgment to be apt, the subject must aptly attain aptness of affirmation. Judgment is affirmation in the endeavour to affirm aptly. In judgment one aims to alethically affirm aptly. Judgmental affirmation that $\mathrm{p}$ must hence manifest competence not only to get it right on the question whether $\mathrm{p}$, but also to do so aptly. In order for a judgment to be apt, the subject must aptly attain aptness of affirmation. However, the importance of the reflective is not explained fully until we see what really matters: namely, that the aptness on the first order be attained under the guidance of the second-order awareness. The performance on the first level must be guided to aptness through the apt second-order awareness (explicit or implicit) that the subject is in that instance competent to avoid excessive risk of failure.

6. Next, let's move from performance-based normativity to action-based normativity (or agent-based normativity). According to Sosa, there are three possible events or states of a human life: they are sufferings (pains or itches) or mere doings (reflex movings), functionings (functionally assessable states), and endeavors (with a freely determined aim) respectively. Human actions can fall between two regions, they can be in the region of freedom (e.g., endeavors) or in a region of passivity (such as sufferings and mere doings). Endeavors can and often do derive from freely determined choices and judgments. They can be sharp or just a matter of degree. Sufferings or mere doings, on the other 
hand, do not involve any freedom or choice. They are passive and often out of the control of their subjects. Because agency involved in human actions are always assessable, in the region of passivity, the subject is in no way of an (action-based) agent. In the region of freedom, the agency involved in the actions or performances which are freely determined endeavors can be either praised or blamed. There is also an intermediate region, which admits a kind of agency, the unfree agency of proper functioning. Agents who merely function are subject to flaws or faults, rather than sins or infractions (or violations). So, we can obtain two frameworks of human actions or agency: (1) Framework I: The loosely deontic framework (one that highlights functional and mechanical faculties): It is an intermediate region, which admits a kind of agency involved in functional actions, the unfree agency of proper functioning. Agents who merely function are subject to flaws or faults, rather than sins or infractions (or violations). (2) Framework II: The more strict deontic framework (one that presupposes free and intentional determination). In the region of freedom, the agency involved in the actions or performances which are freely determined endeavors can be either praised or blamed.

We can also follow what Linda Zagzebski has proposed in her recent works. Zagzebski wants to claim that there are two greatest ideas: (1) the idea that the human mind can grasp the universe, and (2) the idea that the human mind can grasp itself. We can apply the two greatest ideas to the difference between "a person" and "a self", and claim that the idea of a person comes from the idea of the world as a whole, whereas the idea of a self comes from within the mind of a person, where the uniqueness of each person's subjective experience is stressed and leads to a different way of understanding what human dignity is. It is the two greatest ideas that make us a human being (rather than just an animal). Interesting enough, we can also compare these two greatest ideas with a great person in the Chinese tradition: “Inner sageliness (Sagehood, “聖境”), outer kingliness (Kinghood, “王道”)” (“內聖外王” in Chinese). Examining inside ourself, we should reflect on how we can cultivate our virtues, improve our competence, transform our characters, and lead virtuous lives. Carefully considering our own personal position or status among others (in our families, communities, countries, and even the world), we must reflect on how we should play our own roles suitably and properly and lead happy, harmonious and peaceful lives. 
Regarding what the agent, the self, or the "mind" really stands for, we can look back to the history and see how different philosophers expressed their different attitudes and positions.

"I must finally conclude that this proposition, I am, I exist, is necessarily true whenever it is put forward by me or conceived in my mind. . . But I do not yet have a sufficient understanding of what this "I" is, that now necessarily exists. . . But what then am I? A thing that thinks. What is that? A thing that doubts, understands, affirms, denies, is willing, is unwilling, and also imagines and has sensory perceptions." (Descartes, Meditations, II)

"There are some philosophers, who imagine we are every moment intimately conscious of what we call our SELF; that we feel its existence and its continuance in existence; and are certain, beyond the evidence of a demonstration, both of its perfect identity and simplicity. . . . (But) for my part, when I enter most intimately into what I call myself, I always stumble on some particular perception or other, of heat or cold, light or shade, love or hatred, pain or pleasure. I never can catch myself at anytime without a perception, and never can observe any thing but the perception." (David Hume, A Treatise of Human Nature, I, 4, 6)

"My personal identity, therefore, implies the continued existence of that indivisible thing which I call myself. Whatever this self may be, it is something which thinks, and deliberates, and resolves, and acts, and suffers. I am not thought, I am not action, I am not feeling; I am something that thinks, and acts, and suffers. My thought, and actions, and feelings change every moment --- they have no continued, but a successive existence; but that self or $I$ to which they belong is permanent, and has the same relation to all the succeeding thoughts, actions, and feelings, which I call mine." (Thomas Reid, Essays on the Intellectual Powers of Man, Essay 3, Chap. 4). The dialectical style of dialogue among philosophers above has their debates not only on the metaphysical issues regarding "Do I exist? (or am I?)" and "Who am I? (or what is this self or mind?)", but also on the epistemological issues about "How do I know that I exist (or not)?" and "How do I know who I am (or what this self is)?". To avoid the fruitless discussions in metaphysics we have seen from the traditional philosophers, why don't we reflect on the issues from the epistemological perspective? If we reflect on Descartes's idea of "I" (or "self", or "mind"): "I" am a thing that thinks, a thing that doubts, understands, affirms, denies, is willing, is unwilling, and also imagines and has sensory perceptions; it is not so difficult to view the "I", or the "agent" that thinks, 
as a meta-cognitive capacity, while to view all of doubts, understanding, affirming, denying, willing, imagining, and sensory perceptions as the first order cognitive mechanism. The same can go with Hume and Reid. Reflecting on Hume, he claims that "when I enter most intimately into what I call myself, I always stumble on some particular perception or other, of heat or cold, light or shade, love or hatred, pain or pleasure. I never can catch myself at anytime without a perception, and never can observe any thing but the perception". But this idea of "I" or "self", or the "agent" entering the scene, can also be viewed as a meta-cognitive capacity, which is observing all those first-order perceptions. And reflecting on Reid, he wants to argue that "whatever this self may be, it is something which thinks, and deliberates, and resolves, and acts, and suffers. I am not thought, I am not action, I am not feeling; I am something that thinks, and acts, and suffers". But, again, this idea of "self", the "agent" that thinks, and deliberates, and resolves, and acts, and suffers, can also be viewed as a meta-cognitive capacity which has all the first-order cognitions or actions as its objects.

\section{The Master said, in The Analects of Confucius,}

There may be those who act without knowing why. I do not do so. Hearing much and selecting what is good and following it; seeing much and keeping it in memory - this is the second style of knowledge (or a lower level of knowledge)." (ANALECTS, 7.28)

There are actually two parts in this passage. Both of them can be explained and shown to shed light on the distinction between first-level and second-level knowledge. In the first part Confucius distinguishes the kind of knowledge that is needed for action and knowledge that consciously grasps the reasons why one should act as one should. The former kind of knowledge can be categorized as first-level knowledge necessary for carrying out those actions and performances in everyday life. The latter sort of knowledge, however, requires not only that you know how to act or what to do, but also that you know that you know how to act and what to do---that is, the sort of secondlevel knowledge. As we see Confucius endorses the latter, which depends on second-order cognitive competence or mechanism.

He further subordinates first-level knowledge (“識” in Chinese) beneath the sort of knowledge he endorses (“知” in Chinese). Of the second 
part, Confucius goes a step further and clarifies what first-level knowledge is like, while he also delivers his value judgment and subordinates the firstlevel knowledge beneath the sort of knowledge which he is in favour of. The sort of first-level knowledge is acquired mostly through our five senses---you learn from hearing much and seeing much and you keep it in your memory. The resources of what you have learned through those first-order cognitive mechanism and then kept in your memory will later in your life help you recognise or identify them again. They are of course very useful and reliable tools of our everyday life in encountering or steering in the world.

“識” in traditional Chinese sometimes can be simply understood as our memories or to memorize something, and sometimes as the ability of recognizing or identifying something. Whichever it may mean, it all stands for the kind of first-order cognitive abilities or first-level knowledge. But the superior kind of knowledge or knowledge ranked as higher level will require something more which either looks for some superior cognitive mechanism or asks for some higher-order epistemic status. “識” in ancient China can be used interchangeably with the word “誌”. The latter word is mainly meant for the idea of "memory", but the former can mean both "recognition" and “memory”. “識” in its epistemic sense can mean that "recognizing” something (in the new environment) by "remembering" the old situation or experience.

The Master said, "You (由), shall I teach you what knowledge is? When you know a thing, to hold that you know it; and when you do not know a thing, to allow that you do not know it - this is knowledge." (Analects 2.17) The main point of this idea about "what knowledge (the higher-level knowledge) is" indicates the manifestation of the right kind of self-knowledge, which for Confucius requires not only knowing that you know something (when you know it) but also knowing that you don't know something (when you don't know it). It is only when you really know both that you know something and that you don't know something, do you possess the best kind of knowledge. But first what accounts for the difference between simply knowing (merely know something) and possessing knowledge (the kind of self knowledge that knowing that you know and also knowing that you don't know), or going from first-level knowing to second-level knowing, on Confucius's view? Skillfully reflecting on what we are learning or what we know (or knew) can elevate the epistemic status of our knowledge to a higher-level cognitive state or, simply put, to second-level knowledge. Reflection is a dual-aspect secondorder cognitive mechanism. Reflection as thinking forward (or “思”, careful 
thinking ahead over different situations and surrounding environment), let's call it perspective reflection, plays a role like a guiding light which lays out and shines through objective evidence, information, and models in the conscious and conscientious mind of the agent (who is thinking and making a choice of the right way to perform and endeavor to attain his/her goal). Reflection as thinking backward (or “省”, deliberately looking back on the past of oneself), call it retrospective reflection, plays a role like a searching alarm which retrieves and inspects beliefs, thoughts, and representations in the short term or long term memory of the agent who is examining any wrongdoing of his or hers in the past and is seeking his or her best way to avoid or improve them in the future.

8. The Great Learning is also a Confucian text that links reflection with "extended knowledge". The text begins with : "The way of great learning consists in manifesting the manifestation of virtues, in reaching out to others, in achieving ultimate goods”. ( “大學之道, 在明明德, 在親民, 在止於 至善。” in Chinese.) While The Great Learning is concerned with the idea of "reflection" (the higher-order cognitive competence or meta-cognition), it is also concerned with the idea of "extended knowledge". According to The Great Learning, it is the higher-order virtue that can allow us to start on the path to the achievement of the best kind of epistemic goods, such as understanding and wisdom. And we can even extend the epistemic goods beyond ourself, to the community, to the country, and all the way to the world.

The Great Learning instructs us that we should begin with the "comprehension of things". This means that we should, in a systematic way, take in a subject matter or information. Eventually this will allow us to correct our own mind through reflection, and so facilitate the strengthening of openmindedness, intellectual humility and intellectual fairness, and cooperation with others. At the very beginning of The Great Learning, we learn what it is mostly about: 'The way of great learning consists in manifesting the manifestation of virtue, in reaching out to others, and in achieving ultimate goods'. According to the text, when reflection and extended knowledge are appropriately developed, then the final or ultimate goods would be attained. More specifically, higher-order virtues, of which virtuous reflection is an example, puts us in a better position to work towards obtaining the best kind of epistemic goods. We should begin by trying to comprehend the world around us. This means taking in information or a subject matter in a way that 
is systematic. By doing so we are better positioned to weed out errors from our own mind and eventually reach understanding and wisdom - the best kind of epistemic goods.

The other theme of The Great Learning regards "extended knowledge" which concerns epistemic cooperation with others, and requires reflection and consensus. By establishing consensus, a group has peace or harmony which allows it to persist as a social unit and facilitates learning cooperation within the group. This attention to the need for consensus within epistemic groups is an alternative to the common knowledge requirement for group knowledge. While I am not going to make the case for preferring consensus to common knowledge as such a requirement here, my point is to draw the reader's attention to the alternative we get from Confucian thought, which, even if ultimately rejected, can help develop the discourse on this topic.

Both The Great Learning and Ernest Sosa identify four levels of virtue. Sosa categorises these four different levels as: the Primary Level - seat, shape, and situation competences (the SSS competence) are all satisfied and so animal knowledge is possible; the Secondary Level - risk assessment is competently undertaken which allows for reflective knowledge; the Tertiary Level - this level involves virtue that encourages the acquisition and sustainment of primary and secondary levels of virtue; and the Quaternary Level - selecting what is of appropriate value for the application of virtues. According to The Great Learning four levels of virtue must be manifest at both the individual and collective cases in order for great learning to take place. While Sosa's own four levels of virtue has influenced our particular interpretation of the text, we believe that the interpretation of the four levels of virtue is in harmony with the rest of the text. The First Level - Attainment Virtue: this is the sort of virtue that is sufficient for the attainment of some basic goods such as true belief and/or animal knowledge. Such a virtue may operate and have always operated at an entirely sub-personal level. The Second Level - Achievement Virtue: this virtue is such as to allow a success because of reflection to be reckoned an achievement. In order words, an agent who has such a success deserves credit. This is in contrast to success because of Attainment Virtue. Achievement Virtue therefore requires personal level involvement at least somewhere along the line. The Third Level - Intellectual Character Virtue: this virtue maps closely onto how intellectual character-based virtues have been described in the virtue responsibilist literature. In order to sustain the prior two sorts of virtues, this virtue, particularly epistemic humility, is 
required. And the Fourth Level - Meta-Character Virtue: this virtue selects appropriate value-based responses in a given situation. The virtue will help determine whether, for example, a situation calls for intellectual engagement or not, whether one should act on moral or prudential considerations in a given situation.

9. The point of the bi-level virtue epistemology, strictly speaking, is not to propose that there are different kinds of knowledge. The point is rather to emphasize the different kinds of competence which can help us acquire knowledge and gain certain epistemic status: either through the firstorder competence or cognitive mechanism or by adding the second-order competence or meta-cognition on top of the given first-order one. Even for Confucius's two levels of knowledge, the focus of distinguishing different levels of knowledge is not on the "knowledge" per se, but on the different ways of achieving knowledge. For Confucius, the lower-level knowledge can be attained simply by our five senses or memory, while the higher-level (or the best kind of) knowledge can only be achieved by manifesting our skillful reflection.

To make this bi-level virtue epistemology more clearly and more significantly, it is important to notice the following different types of cognitive or psychological processes: simply seeing (hearing, smelling, tasting, and touching), simply memorizing, simply reasoning, and simply introspecting, let's call these the type-one processes; reflectively (attentively, or consciously) seeing (hearing, smelling, tasting, and touching), reflectively (attentively, or consciously) memorizing, reflectively (attentively, or consciously) reasoning, and reflectively (attentively, or consciously) introspecting, let's call all of these the type-two processes. The type-one processes, cognitive or psychological, involve only the first-order cognitive mechanism, while the type-two processes apply not only the first-order cognitive mechanism, but also the metacognition or higher-order competence. It is also important to realize the fact that we cannot have only employed our higher-order cognition without using or functioning any first-order cognitive mechanism, in which case it is like to reflect on, be conscious of, or pay attention to nothing at all.

In the modern usage of Chinese language, the ways of expression concerning our cognitive processes or psychological states usually consist of and combine two different Chinese characters, for examples, sense perceiving 
by the expression of 感覺, thinking by 思想, hearing by 聽聞, seeing by 看 見, and many more. However, these two-word expressions all combine and confuse the different levels of cognitive mechanism or processes in question. “感覺” combines the word “感” which means “sensing” (first-order cognitive sensing) and the word “覺” which means "consciousness" (higher-order cognitive state). “思想” combines the word “思” meaning “reflecting” (metacognition) and the word “想” meaning “merely thinking” (first-order cognitive mechanism). “聽聞” combines the word “聽” meaning "hearing” (first-order cognitive sensing) and the word “聞” meaning "listening carefully or hearing attentively” (higher-order cognitive mechanism). And “見識” combines the word “看” meaning "seeing” (first-order cognitive sensing) and the word " 見” meaning “watching carefully or seeing attentively" (higher-order cognitive mechanism). Ironically, all those Chinese words above were used individually in ancient history of Chinese philosophy (without combining with others), and can stand for their own proper cognitive or psychological states without confusing their different levels of epistemic status.

10. The common-sense of forgetting has always been negative, as it is understood as memory-loss, or retrieval failure. However, thanks to the efforts of some philosophers and psychologists, the positive side of forgetting has started being recognized. Now, under the proposed bi-level virtue epistemology, our cognitive processes can occur in two different types. The memory process in the issue here which usually functions as the first-order cognition (as the typeone cognitive process, such as sense perception, reasoning or introspection) by default can also become as the object being reflected on, being paid attention to, or being conscious of, and therefore works as part of the second-order cognition (as the type-two cognitive process). It follows that the conception of forgetting can also be embedded in this framework of memory process: the phenomenon of forgetting can occur during the type-one cognitive process or the type-two cognitive process.

In addition to this bi-level cognitive process, we also have the model of memory as a 3-RE process as proposed above. The concept of "forgetting", therefore, can have many different faces depending upon when the phenomenon of forgetting take place and whether it does so as the firstorder (automatically or passively) capacity or as the second-order capacity (reflectively or attentively or actively). Following and contrasting with the memory process which may sometimes function as the first-order condition 
or sometimes as a part of the meta-cognition, forgetting can behave like inattentively unnoticed or attentively ignoring at the RE-1, permanently lost or systematically recycling (or sedimenting) at the RE-2, and incompetently retrieving or capably abstracting (or omitting) at the RE-3. Based on this taxonomy, it will be clearly seen how the uncommon-sensical concepts of forgetting can sometimes play an important and positive role in epistemic internalism, epistemic externalism and virtue epistemology, regarding how we acquire or achieve knowledge. Let's re-consider and re-evaluate the password case mentioned above. Ernie's decision of forgetting the long series digit password given by his bank (plus securely saving it in his secret pocket book) is a justified way of knowing the password for epistemic internalism, a reliable way of gaining knowledge of the password for epistemic externalism, and a virtuous or competent way of achieving knowledge of the password for virtue epistemology, because as soon as he receives the password he deliberately forgets the password rather than remembers it. For Ernie, to forget is better than to remember in this case. Ernie knows full well that he cannot remember the long series digit number, and the best way to keep this important number is not to force himself memorising the number but to (forget it and) save it in a secured place (the secret pocket book in this case) and to retrieve the number from the pocket book when it is needed in the future.

The problem of forgetting designates the paradoxical character of forgetting that it is not only a vice but also a virtue. If forgetting can be understood from the perspective offered above, then one needs not to be fear more than one commonly expects to be.

MI, C. Memória e reflexão. Trans/form/ação, Marília, v. 44, p. 151-168, Edição Especial Dossier "Ernest Sosa”, 2021.

Resumo: Eu argumento que os Analectos de Confúcio nos apresentam uma concepção de reflexão com dois componentes, um componente retrospectivo e um componente perspectivo. O primeiro componente envolve uma retrospectiva ou um exame cuidadoso do passado e, como tal, recorre à aprendizagem ou memória e a crenças previamente formadas para evitar erros. O segundo componente é prospectivo e, como tal, olha para as crenças e fatores atuais a fim de alcançar o conhecimento. Neste artigo, levanto o problema do esquecimento e defendo que a maioria das teorias contemporâneas do conhecimento têm de enfrentar o problema e lidar seriamente com esse desafio. A fim de 
resolver o problema, sugiro uma epistemologia de virtude a dois níveis que nos possa fornecer a melhor perspectiva para a resolução do problema. Irei correlacionar duas capacidades cognitivas ou processos diferentes de "memória" (e de "esquecimento") com a concepção de reflexão, e avaliá-losei sob dois enquadramentos diferentes, um enquadramento deontológico rigoroso (que pressupóe uma determinação livre e intencional) e um enquadramento deontológico mais fraco (que realça as faculdades funcionais e mecânicas). O objetivo é mostrar que a reflexão como metacognição desempenha um papel importante e ativo e goza de um melhor estatuto epistêmico (normativo) nos nossos esforços humanos (cognitivo ou epistêmico) do que os de primeira ordem (ou de cognição animal), tais como a memória, podem desempenhar.

Keywords: Memória. Virtude Epistemologia. Reflexão.

\section{REFERENCES}

BERNECKER, S., \& GRUNDMANN, T. Knowledge from Forgetting. Philosophy and Phenomenological Research, 98(3), p. 525-540, 2019.

DESCARTES, R. (1641). Meditations on First Philosophy. In The Philosophical Writings of Descartes: Volume 2, translated by J. Nottingham, R. Stoothoff, and D. Murdoch. Cambridge University Press, 1984.

HUME, D. (1739). A Treatise of Human Nature. Ed. By D. F. Norton and M. J. Norton. Oxford : Oxford University Press, 2000.

LOCKE, J. (1690). An Essay Concerning Human Understanding. Oxford : Oxford University Press, 2000.

MADISON, B. J. C. “Epistemic Internalism, Justification, and Memory.” Logos \& Episteme, 5(1), p. 33-62, 2014.

MELTON, A. W. "Implications of Short-Term Memory for a General Theory of Memory." Journal of Verbal Learning and Verbal Behavior, 2, p. 1-21, 1963.

MI, C. What Is Knowledge? When Confucius Meets Ernest Sosa. Dao: A Journal of Comparative Philosophy, Vol. 14, No. 3, p. 355-367, 2015.

MI, C. \& TAN, M. T. (Forthcoming). The Problem of Forgetting.

MICHAELIAN, K. The Epistemology of Forgetting. Erkenntnis, 74(3), p. 399-424, 2011.

REID, T. (1785). Essays on the Intellectual Powers of Man. The Works of Thomas Reid. Vol I. London : Elibron Classics, 2005.

SOSA, E. Knowing Full Well. New York: Princeton University Press, 2011.

SOSA, E. Judgment and Agency. Oxford: Oxford University Press, 2015.

Received: 06/10/2020

Approved: 05/3/2021 